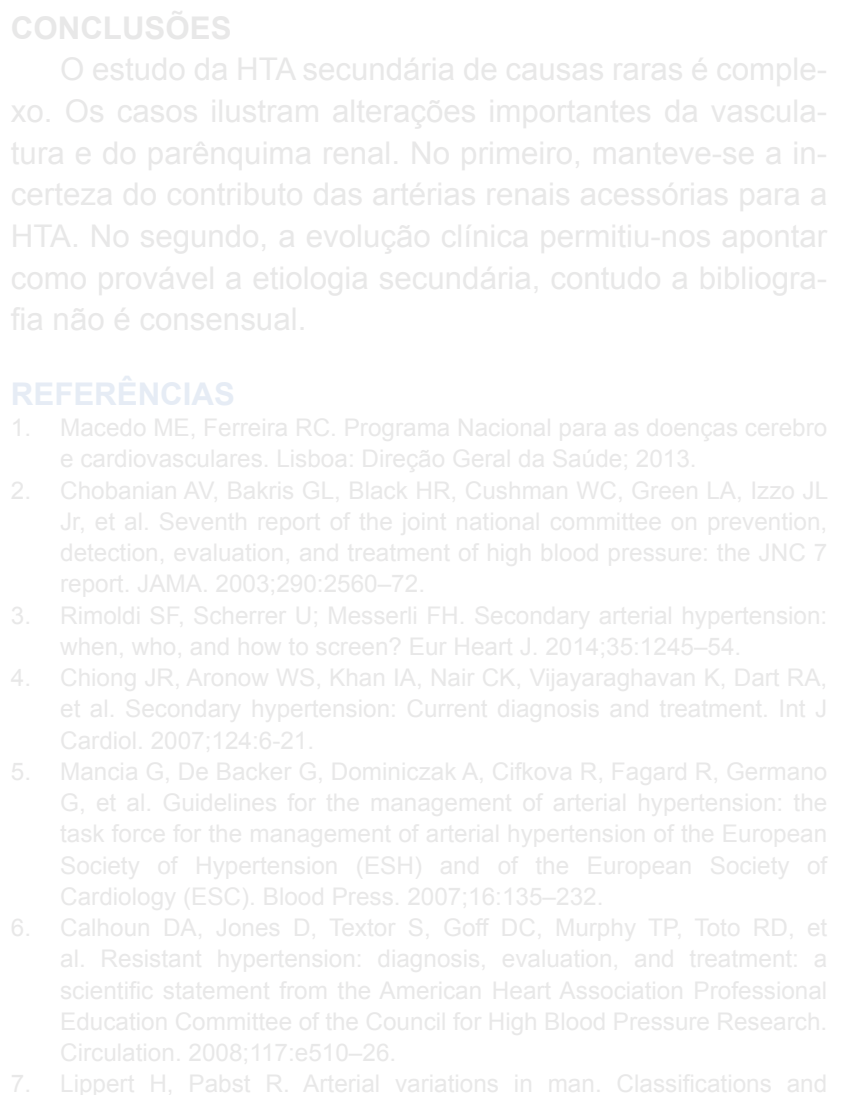

\title{
Klebsiella pneumoniae do Serotipo K1 e do Clone Hipervirulento ST23: Primeiro Caso Documentado em Portugal
}

\section{Klebsiella pneumoniae from K1 and Hypervirulent Clone ST23: First Documented Case in Portugal}

\author{
Aida PEREIRA ${ }^{1}$, Tiago PETRUCCl², Maria João SIMÕES ${ }^{3}$ \\ Acta Med Port 2017 Jun;30(6):496-499 - https://doi.org/10.20344/amp.7705
}

\section{RESUMO}

A estirpe híper-virulenta Klebsiella pneumoniae serotipo K1 é responsável por uma síndrome invasiva infeciosa, caracterizada por abcessos hepáticos com manifestações extra-hepáticas. Inicialmente identificada em Taiwan, tem aumentado significativamente em vários países da Ásia, e mais recentemente na Europa e América do Norte, conferindo a esta entidade um caracter emergente e global. Os autores apresentam o caso clinico de uma mulher de 64 anos, caucasiana, portuguesa, sem antecedentes pessoais ou epidemiológicos como viagens ou exposição a produtos asiáticos, na qual foi diagnosticada, abcesso hepático piogénico complicado de derrame pleural por esta estirpe híper-virulenta. Após conhecimento do diagnóstico e instituição de terapêutica antibiótica combinada com drenagem percutânea, foi possível a resolução do caso clínico com sucesso. Este caso permitiu a identificação do primeiro caso de síndroma invasiva infeciosa, por Klebsiella pneumoniae do clone híper-virulento ST23 documentado em Portugal.

Palavras-chave: Abscesso Hepático; Infecções por Klebsiella; Klebsiella pneumoniae; Portugal

\section{ABSTRACT}

The hypervirulent K1 serotype Klebsiella pneumoniae is responsible for a new invasive syndrome, typically associated to hepatic abscesses with extra-hepatic complications. Initially described in Taiwan, it has significantly spread to several Asian countries and

1. Serviço de Doenças Infecciosas. Hospital de Santa Maria. Centro Hospitalar de Lisboa Norte. Lisboa. Portugal.

2. Serviço de Medicina I. Hospital de Santa Maria. Centro Hospitalar de Lisboa Norte. Lisboa. Portugal.

3. Unidade Laboratorial Integrada. Departamento de Doenças Infecciosas. Instituto Nacional de Saúde Doutor Ricardo Jorge. Lisboa. Portugal.

$\triangle$ Autor correspondente: Aida Pereira. aida_pereirav@yahoo.com.br

Recebido: 04 de abril de 2016 - Aceite: 06 de março de 2017 | Copyright $\odot$ Ordem dos Médicos 2017 
more recently to Europe and North America, thus constituting an emerging and global problem. The authors describe a case report of a 64-years-old portuguese caucasian woman without any previous diseases or epidemiological risk factors such as trips or contact with Asian products or population, diagnosed with a pyogenic liver abscess with pleural effusion caused by this hyper-virulent strain. A successful clinical cure was achieved after the etiological identification and treatment with antimicrobial therapy combined with catheter drainage. This is the first identification of hypervirulent Klebsiella pneumonia ST 23 clone in Portugal in the context of an invasive syndrome.

Keywords: Klebsiella Infections; Klebsiella pneumonia; Liver Abscess; Portugal

\section{INTRODUÇÃO}

Klebsiella pneumoniae (K. pneumoniae) é um bacilo Gram negativo responsável pela pneumonia adquirida na comunidade, particularmente em indivíduos alcoólicos, no entanto em doentes imunodeprimidos, com comorbilidades tais como diabetes mellitus, está associada a infeções nosocomiais do trato urinário, pneumonia, septicemia e infeções intra-abdominais. Nos países desenvolvidos, a pneumonia da comunidade por $K$. pneumoniae tem diminuído nas últimas décadas, emergindo nos países asiáticos uma síndrome clínica distinta invasiva, causada por uma estirpe híper-virulenta de $K$. pneumoniae, caracterizada por abcessos hepáticos com complicações extrahepáticas, incluindo meningite, fasceíte necrosante ou endoftalmite. ${ }^{1,2,3}$

A estirpe híper-virulenta de K. pneumoniae (hvKP) acima referida foi descrita pela primeira vez em Taiwan (1985) e posteriormente noutros países asiáticos. ${ }^{2} \mathrm{~A}$ epidemiologia do abcesso hepático mudou radicalmente nos últimos anos. Anteriormente, apesar de rara, a doença era caracterizada pela gravidade e mortalidade elevada, devido à presença de patologia hepatobiliar subjacente, à etiologia polimicrobiana, representando Escherichia coli o principal agente patogénico. ${ }^{2,4,5}$

K. pneumoniae, conhecido como agente nosocomial oportunista, associado muitas vezes à diabetes mellitus, tem vindo a emergir nas infeções adquiridas na comunidade, com características invasivas, metastáticas, e com elevada frequência de abscessos hepáticos piogénicos. ${ }^{6,7}$

Os principais fatores de virulência relacionados com $K$. pneumoniae são $O$ antigénio somático $O(O 1)$ e antigénio capsular K (K1 e K2). Contudo, os isolamentos de hvKP nos abcessos hepáticos têm sido associados a fatores de virulência específicos, nomeadamente, a aerobactina alls, kfu e rmpA (regulador do fenótipo mucóide). Este último, associado a híper-muco-viscosidade, torna esta estirpe resistente à fagocitose e responsável pela natureza invasiva de algumas estirpes de K. pneumoniae. ${ }^{1} \mathrm{O}$ gene MagA, originalmente proposto como fator de virulência, foi demonstrado ser parte do agrupamento de genes da cápsula polissacarídica K1. Entretanto o estudo da estrutura de $K$. pneumoniae por tipagem multilocular sequencial - multilocus sequence typing (MLST) - demonstrou um perfil clonal do serotipo capsular híper-virulento K1, pertencente à sequência tipo ST23, associado a abcessos hepáticos piogénicos. ${ }^{6}$

Tal como descrito em Taiwan e no sudeste asiático, têm sido reportados casos esporádicos de abcessos hepáticos por hvKp nos Estados Unidos da América (EUA), Canadá, Espanha, França, Bélgica, Suécia e Dinamarca, muitas vezes relacionados com viagens ou processos migratórios, ${ }^{6}$ embora estes dados epidemiológicos possam estar ausentes. Os autores reportam o primeiro caso de abcesso hepático piogénico por $K$. pneumoniae do clone híper-virulento ST23 documentado em Portugal numa doente sem comorbilidades ou fatores epidemiológicos.

\section{CASO CLÍNICO}

Mulher portuguesa de 64 anos, caucasiana, doméstica, hipertensa, controlada com nebivolol e associação de ramipril e hidroclorotiazida, com consumo de meio copo de vinho por dia e hábitos tabágicos de 10 - 12 unidades maço / ano. Sem história de viagens ou exposição a produtos de origem asiática.

Internada por quadro com nove dias de astenia, anorexia, febre, calafrios e sudorese, apresentando diarreia nas primeiras 48 horas. Objetivou-se tensão arterial 95/55 $\mathrm{mmHg}$, pulso-102 ppm, temperatura timpânica $38,9^{\circ} \mathrm{C}$, crepitações pulmonares localizadas no terço inferior bilateralmente, abdómen mole, depressível, indolor e sem hepatoesplenomegalia. $\mathrm{O}$ estudo analítico documentou leucocitose $(17610 \times 10 \%$ L) com neutrofilia $(84 \%)$ e proteína C-reativa de 29,2 mg/dL, função renal e hepática normais. A radiografia do tórax evidenciou reforço reticular bilateral, ingurgitamento hilar e parahilar direito com apagamento do seio costo frénico esquerdo. Após colheita de sangue e urina para estudo microbiológico (negativos), iniciou ciprofloxacina por suspeita de infeção com ponto de partida abdominal, posteriormente substituída por ceftriaxona por ausência de resposta clínica e analítica. Ao quinto dia de internamento realizou ecografia abdominal que mostrou abcesso hepático de $9,5 \mathrm{~cm} \times 8,5 \mathrm{~cm}$, no lobo esquerdo e derrame pleural bilateral. A tomografia computorizada (TC) torácica mostrou focos de densificação do parênquima pulmonar no lobo inferior esquerdo e pequeno derrame pleural bilateral de maior volume à esquerda. A punção aspirativa ecoguiada do abcesso drenou material purulento muito espesso, com isolamento de K. pneumoniae, resistente à ampicilina, sensível à amoxicilina/àcido clavulânico, cefuroxime, co-trimoxazol e gentamicina, mantendo a mesma antibioterapia. Face às características macroscópicas de híper-muco-viscosidade em cultura procedeu-se à sequenciação completa do genoma, no Instituto Nacional de Saúde Pública Dr. Ricardo Jorge, usando o esquema MLST, que identificou a sequência tipo ST23 e provável serotipo capsular K1. No internamento, observou-se deterioração clínica com insuficiência respiratória, necessidade de oxigenoterapia e agravamento do derrame pleural principalmente à esquerda na TC torácica. Através da toracocentese, drenou de $1050 \mathrm{~mL}$ de exsudado, com cultura do líquido 

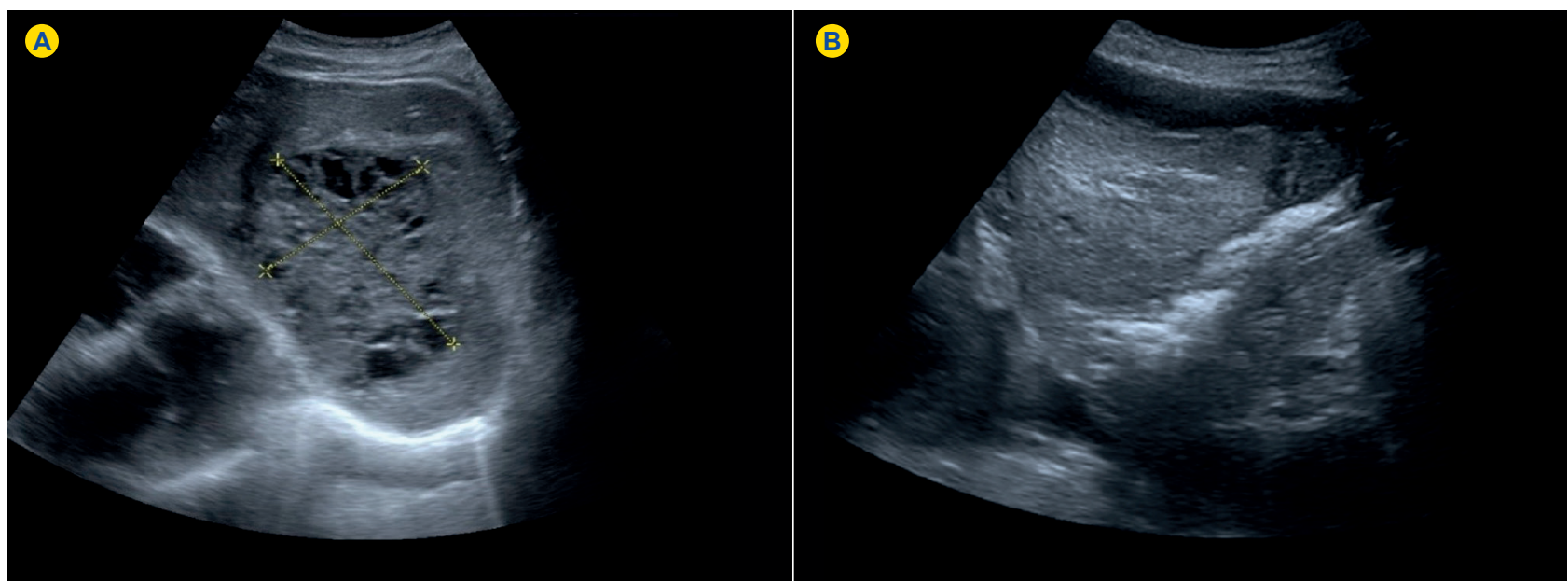

Figura 1 - Ecografia abdominal revelando (A) abcesso no lobo esquerdo do fígado e ecografia abdominal (B) de controlo com redução acentuada da área abcedada após antibioterapia

e biopsia pleural negativos.

A doente cumpriu 30 dias de antibioterapia endovenosa, com diminuição ecográfica do abcesso, tendo alta medicada com amoxicilina e ácido clavulânico oral durante dois meses e meio. Após a sua suspensão em ambulatório, foi considerada curada ao fim de três meses, dada a persistência de parâmetros inflamatórios negativos e resolução imagiológica (Fig.s 1A, 1B).

\section{DISCUSSÃO}

$\mathrm{O}$ aumento da prevalência de $K$. pneumoniae serotipo K1 como agente responsável de abcessos hepáticos tem sido relatado em países asiáticos, especialmente em Taiwan e Coreia. ${ }^{8}$ Nestes países, $K$. pneumoniae tornou-se a etiologia mais comum de abcesso hepático nas últimas décadas, contrariando o antigo dogma de que os abcessos hepáticos piogénicos resultam de infeção poli-microbiana incluindo aeróbios, nomeadamente Escherichia coli e anaeróbios. Este serotipo $\mathrm{K} 1$ tem sido, no entanto, raramente identificado nos países ocidentais, não estando esclarecida a razão da sua emergência. ${ }^{4.59}$

Um grupo de investigadores coreanos realizou um estudo caso-controlo de uma população de 78 doentes com abcesso hepático por $K$. pneumoniae serotipo K1 confirmado, aferindo várias variáveis como possíveis fatores de risco para o seu desenvolvimento, tendo concluindo que a diabetes mellitus foi o fator de risco mais significativo, não se estabelecendo correlação entre a patologia das vias biliares e esta entidade. Nos doentes não diabéticos $(52,6 \%)$ outros fatores foram considerados, como: suscetibilidade genética, etnia, colonização intestinal, exposição ambiental e condições sócio-económicas. As diferenças epidemiológicas sugerem que a etnicidade pode ter impacto no desenvolvimento desta doença. . $^{1,9}$

Foi recentemente identificado em áreas de alta prevalência $K$. pneumoniae serotipo K1 ST23 nas fezes de portadores assintomáticos e saudáveis, com semelhanças genotípicas com o agente isolado nas fezes de doentes com abcessos hepáticos. Tem sido sugerido que esta colonização antecipa a invasão da mucosa intestinal e do sistema porta ou da via biliar, precedendo a formação do abcesso hepático. ${ }^{10}$

De igual modo, a idade, tradutora do tempo de exposição a fatores ambientais e consequente probabilidade de aquisição desta estirpe, é um fator de impacto no desenvolvimento desta doença (ex: adultos com idade inferior a 25 anos estavam menos colonizados por $K$. pneumoniae serotipo $\mathrm{K} 1$ e o diagnóstico de abcesso hepático por este agente ocorreu habitualmente aos 60 anos). Estes fatores podem desempenhar um papel importante na colonização desta estirpe, o que explica as diferenças geográficas na epidemiologia do abcesso hepático por K. pneumoniae..$^{10}$

$\mathrm{Na}$ doente apresentada, não foi possível estabelecer uma cadeia epidemiológica evidente, dada a ausência de fatores de risco (comorbilidades, viagens, contactos com produtos ou população asiática). No entanto, tal como descrito na literatura, a doente encontrava-se na faixa etária de maior prevalência de casos de abcessos $h v K P$, com invasão metastática (pulmonar) e com o mesmo perfil de sensibilidade antibiótica tal como descrito na literatura (resistência à ampicilina).$^{9}$

$\mathrm{O}$ isolamento microbiológico de $K$. pneumoniae e a identificação da estirpe por técnicas moleculares faz o diagnóstico definitivo. Ainda assim, dado o fenótipo de híper-muco-viscosidade, as colónias desta estirpe formam um filamento de muco espesso, $(>0,5 \mathrm{~cm})$, quando estiradas por uma ansa de inoculação no meio de cultura. ${ }^{1}$

Os autores sugerem como hipótese do aparecimento desta estirpe, a possibilidade de ser endémica, circulando em pequeno número na comunidade, ou que a doente faça parte de uma cadeia de infeção por K. pneumoniae com o clone ST23 não esclarecida. A associação dos casos nos EUA e na Europa com a origem asiática, favorece mais a hipótese de que esta estirpe faça parte de uma cadeia epidemiológica em desenvolvimento e possa constituir um problema importante de saúde pública mundial. ${ }^{6}$

\section{CONCLUSÃO}

Uma possível explicação para a identificação do caso português de estirpe híper-virulenta de $K$. pneumoniae 
numa doente sem comorbilidades ou contacto direto com produtos ou população asiática poderá ser a aquisição do agente através de exposição ambiental local. A presença desta estirpe no meio ambiente pode resultar da imigração asiática e consequente importação dos seus produtos e hábitos alimentares, assim como a sua flora comensal. Por outro lado, não é de desvalorizar o contacto, resultante da globalização e deslocação da própria população portuguesa a países endémicos, importando consequentemente a flora local. Do ponto de vista de saúde pública, seria de todo o interesse fazer um estudo epidemiológico da comunidade geral (através do rastreio das fezes de potenciais portadores assintomáticos), com o objetivo de controlo da disseminação deste e de outros agentes altamente virulentos.

\section{AGRADECIMENTOS}

Os autores agradecem ao responsável do Serviço de Microbiologia, Luís Marques Lito, pelo seu contributo na identificação e sequenciação genética da estirpe híper-vi-

\section{REFERÊNCIAS}

1. Siu LK, Yeh KM, Lin JC, Fung CP, Chang FY. Klebsiella pneumoniae liver abscess: a new invasive syndrome. Lancet Infect Dis. 2012;12:8817.

2. Podschun R, Ullmann U. Klebsiella spp. as nosocomial pathogens: epidemiology, taxonomy, typing methods, and pathogenicity factors. ClinMicrobiol Rev. 1998;11:589-603.

3. Ko WC, Paterson DL, Sagnimeni AJ, Hansen DS, Von Gottberg A, Mohapatra S, et al. Community-acquired Klebsiella pneumoniae bacteremia: global differences in clinical patterns. Emerg Infect Dis. 2002;8:160-6.

4. Wang JH, Liu YC, Lee SS, Yen MY, Chen YS, Wang JH, et al. Primary liver abscess due to Klebsiella pneumoniae in Taiwan. Clin Infect Dis. 1998;26:1434-8.

5. Tsai FC, Huang YT, Chang LY, Wang JT. Pyogenic liver abscess as endemic disease, Taiwan. Emerg Infect Dis. 2008;14:1592-600.

6. Gundestrup S, Struve C, Stahlhut SG, Hansen DS. First case of liver abscess in Scandinavia due to the international hypervirulent Klebsiella rulenta de K. pneumoniae do caso clínico apresentado.

\section{PROTECÇÃO DE PESSOAS E ANIMAIS}

Os autores declaram que os procedimentos seguidos estavam de acordo com os regulamentos estabelecidos pelos responsáveis da Comissão de Investigação Clínica e Ética e de acordo com a Declaração de Helsínquia da Associação Médica Mundial.

\section{CONFIDENCIALIDADE DOS DADOS}

Os autores declaram ter seguido os protocolos do seu centro de trabalho acerca da publicação de dados.

\section{CONFLITOS DE INTERESSE}

Os autores declaram não terem qualquer conflito de interesse relativamente ao presente artigo.

\section{FONTES DE FINANCIAMENTO}

Os autores declaram que o trabalho não foi objeto de qualquer financiamento.

pneumoniae clone ST23. Open Microbiol J. 2014;8:22-4.

7. Yu VL, Hansen DS, Ko WC, Sagnimeni A, Klugman KP, von Gottberg A et al. Virulence characteristics of Klebsiella and clinical manifestations of K. pneumoniae bloodstream infections. Emerg Infect Dis. 2007;13:98693.

8. Chung DR, Lee HR, Lee SS, Kim SW, Chang HH, Jung SI, et al. Evidence for clonal dissemination of the serotype K1 Klebsiella pneumoniae strain causing invasive liver abscesses in Korea. J ClinMicrobiol. 2008;46:4061-3.

9. Kim JK, Chung DR, Wie SH, Yoo JH, Park SW, Korean Study Group for Liver Abscess. Risk factor analysis of invasive liver abscess caused by the K1 serotype Klebsiella pneumoniae. Eur J Clin Microbiol Infect Dis. 2009;28:109-11.

10. Chung DR, Lee H, Park MH, Jung SI, Chang HH, Kim YS, et al. Fecal carriage of serotype K1 Klebsiella pneumoniae ST23 strains closely related to liver abscess isolates in Koreans living in Korea. Eur J Clin Microbiol Infect Dis. 2012;31:481-6. 